\title{
Large Mammal Fauna of the Afadjato and Agumatsa Range in Ghana: An Important Bird Area
}

\author{
E. H. Owusu*, E. K. Ekpe and A. Asamoah \\ Ghana Wildlife Society, P. O. Box 13252, Accra, Ghana \\ *Corresponding author
}

\begin{abstract}
The Mount Afadjato and Agumatsa Range Conservation Area (AACA) is one of the globally important bird area in Ghana, currently being managed through community-based conservation actions by local people with the support of the Ghana Wildlife Society. As in many other Ghanaian communities the mammal fauna of the site continue to decline as a result of many factors, basically anthropogenic in origin. The aim of the study was to assess the status of large mammals in the area in terms of their diversity, relative abundance, density, and species of local, national and international conservation concern, and the factors likely to affect these variables. The diversity, relative abundance and densities of mammal species at the site are one of the lowest in Ghanaian forests. There is every indication that the major factors causing the decline in mammal population in the area are habitat degradation and hunting pressure. As in many other communities in the West African sub-region, all mammals are negatively impacted upon by human activities. Consequently, given that whatever activities being proposed by the locally initiated community-based conservation programme will greatly depend on availability of wildlife, especially for ecotourism, there is a need for a more pragmatic approach to conserve the remaining wildlife without further delay.
\end{abstract}

\section{Introduction}

The delicate balance that needs to be developed between the complex and fragile ecosystems of the tropical rainforest is perplexing (Bodmer, 1995). As a result, wildlife abundance and diversity continue to decline. In West Africa, the decline has been on a large scale for the last 300-400 years especially for mammalian fauna (Decher, Kilpatrick \& Bahian, 2000). Several reasons have been proposed for this decline. Prominent among them is the decline in original habitat, which has been observed at the global level to be the most common cause of population decline and species extinction (Stewart \& Hutchings, 1996; Mace \& Balmford, 2000). It has been estimated that 36\% of animal extinctions, where the cause is known, were due to habitat destruction (Jenkins, 1992). Another estimate suggests that habitat destruction is responsible for the extinction of over 100 species daily (Ehrlich \& Wilson, 1991). The other major cause of extinctions is hunting pressure, which continues with increasing human populations in local communities around forests. Thus, there is now widespread agreement that many threats to species are anthropogenic in origin (Stewart \& Hutchings, 1996; Ghimire \& Pimbert, 1997).

In the Afadjato and Agumatsa Conser-vation Area (AACA), declines in mammal numbers have been attributed mainly to hunting and perennial bush fires, both intentional and accidental. Shifting cultivation both on the mountain slopes and in the lowlands have also been identified by the local people as contributing to loss of habitat, and, consequently, decline of wildlife, particularly mammals, in the area. Therefore, mammal sightings have become very rare in the AACA. However, the area has not been studied sufficiently to arrive at any definite conclusions concerning the status of mammals. The only study that was undertaken by the Ghana Wildlife Society (GWS, 1998) concentrated on small mammals and bats, with only casual observations on the occurrence of large mammal species. This paper is an attempt to document the occurrence of large mammals in AACA in terms of their diversity, relative abundance, density, and species of local, national and international conservation concern.

\section{Material and methods}

Study area

The AACA comprising Mount Afadjato and the Agumatsa Range is an important bird area (IBA) and is part of the Akwapim-Togo Range, which constitutes the highest hills in Ghana. Mount Afadjato itself is the highest mountain in Ghana, at $890 \mathrm{~m}$ above sea level. Agumatsa Range runs in a northeast to southwest direction between the Volta River and the Togo border (Ntiamoa-Baidu et al., 2001). The hills lie within longitude $0^{\circ} 15^{\prime} \mathrm{E}$ and $0^{\circ} 45^{\prime} \mathrm{E}$ and latitude $6^{\circ}$ 45' and $7^{\circ} 15^{\prime} \mathrm{N}$. The Agumatsa Range is a distinct landmass with Wli and Tagbo waterfalls at the northern and southern borders, respectively. The study area is located in the Hohoe District, bordered on the east by the Republic of Togo, on the west by Kpando District, on the north-west by Jasikan District and on the south by Ho District. The study villages lie at the foot of the Agumatsa Range and include: Gbledi-Gborgame, Gbledi-Chebi, Fodome-Ahor, Wli-Afegame and Wli-Agorviefe (Fig. 1). Together, the villages cover an area about $1172 \mathrm{~km}^{2}$. For the purpose of this study, the whole area is referred to as Afadjato and Agumatsa Conservation Area (AACA). 


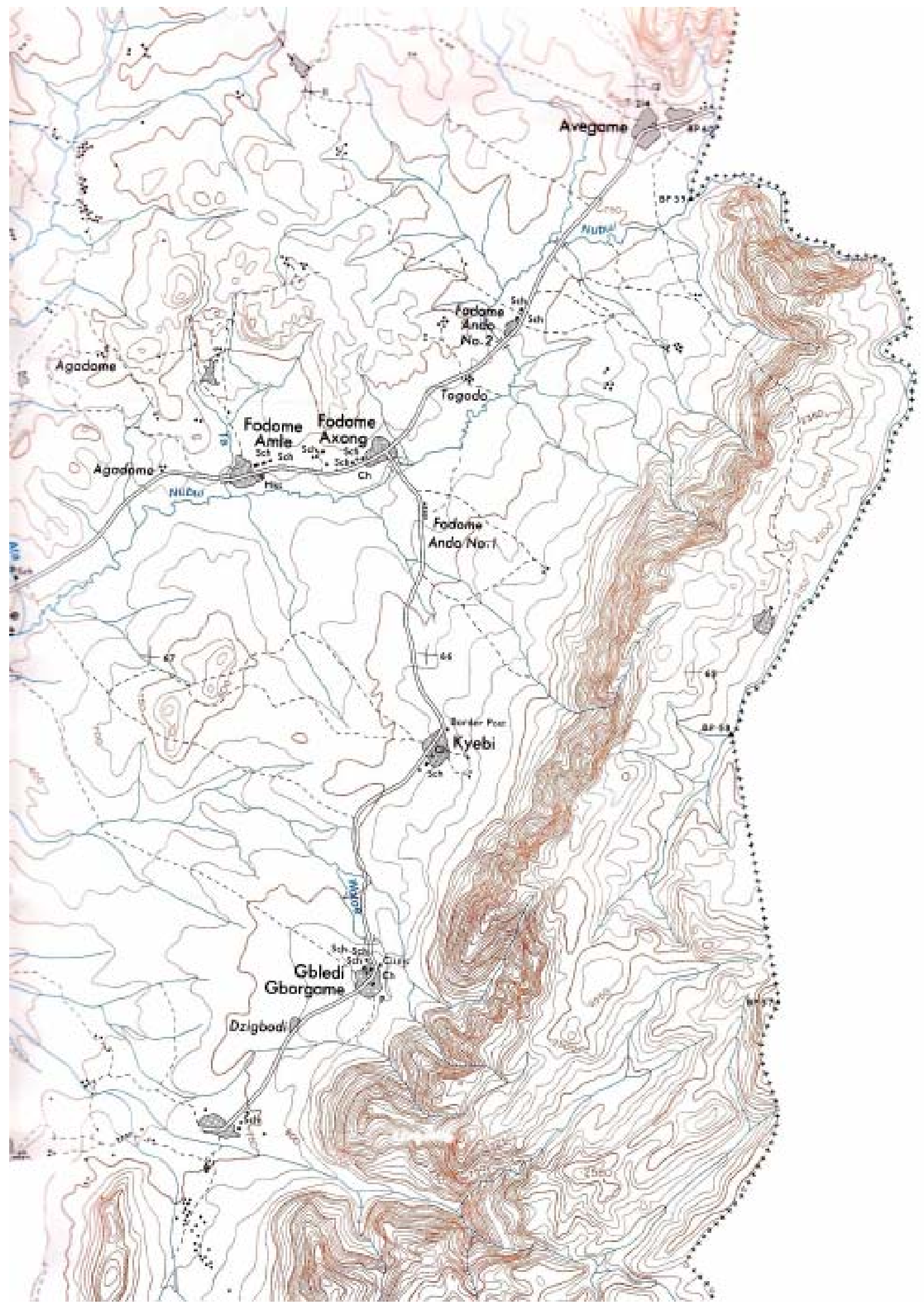

Fig. 1. Map of study area showing major villages 
The two localities of Gborgame and Chebi were selected for the survey. For each locality, the range was divided into the two habitat types of lowland forest and highland (sub-montane to grassland habitat), giving four sampling sites. Several standard methods are currently available for use in surveys of terrestrial mammalian fauna (Wilson et al., 1997). The methods that were used in this study, notably direct observation on transect walks, trail surveys, night surveys, and interviews of local people are outlined below.

Transect survey. Transect surveys were undertaken in all the sites with a total of 16 sampling days allocated for the surveys in both habitat types in each of the localities, spread over a period of 8 months. Each survey lasted for $4 \mathrm{~h}$ with the survey team comprising the investigator and two other assistants from the study area, including an experienced hunter. One 3-km transect was walked in each of the two habitat types in each locality. Since each transect was walked twice per survey, the total transect effort totalled $6 \mathrm{~km}$ per habitat in each of the localities per survey period. Thus, the total transect length for the two surveys of each locality totalled $24 \mathrm{~km}$. Night surveys covering a distance of about $5 \mathrm{~km}$ on hunters' trails were conducted once per survey period for the possible detection of nocturnal mammals. Both direct and indirect observa-tions were used. The indirect observations involved transect walks to spot animals or their spoor (any sign left by a living animal, such as feeding sites, regular pathways, tracks, footprints, faecal pellets, nests, etc). For each sighting, the perpendicular distance of the animal from the transect was recorded, as were the activities at the time of sighting.

Opportunistic surveys. Opportunistic and ad hoc surveys involved recording all sightings of mammal species, which the survey team encountered during avifauna surveys (Owusu, 2001) and outside the systematic mammal surveys, including carcasses brought to the 'chop-bar' at Gborgame.

Interviews. The interviews took two forms. The first was with hunters' groups and the only 'chop-bar' operator, where $3 \mathrm{~h}$ was spent with each of the groups in the three villages of Gborgame, Chebi and Ahor. The group interviews were aimed at obtaining information on possible occurrence of species that might be present in the area, but not sighted in the field counts. The hunters and other respondents were encouraged to express themselves freely in an informal and relaxed atmosphere. They were shown field guides and manuals (Haltenorth \& Diller, 1988; Kingdon, 1997) to help them identify the animals from drawings or pictures. This approach ensured that the information obtained, especially on mammal identification, could be corroborated or disputed by others.

\section{Data analysis}

Mammal species diversity and abundance. The Shannon-Wiener diversity index (Magurran, 1988) was used to determine species diversity. Species abundance was based on frequency of sightings, which is expressed as relative abundance of individual species. One way analysis of variance (ANOVA) was used to compare values for sites. Similarity of sites follows the Sorenson Indices:

$C s=2 j /(a+b)-$ qualitative and $C N=2 j N /(a N+b N)$ - quantitative, where $J=$ the number of species found in both sites; $a=$ the number of species in site A; $b=$ the number of species in site $\mathrm{B}$; $a N=$ the total number of individuals in site $\mathrm{A} ; b N=$ the total number of individuals in site $\mathrm{B}$; and $j N=$ the sum of the lower of the two abundances.

The qualitative index was used to compare the occurrence of species, while the quantitative index was used to compare the relative abundance of individual animal encounters at the four sites. The indices are designed to be equal to one (1) in case of complete similarity (Magurran, 1988).

Estimation of densities. The Programme "Distance" 3.5, release 5 (Buckland et al., 1999) was used to estimate the densities of the mammal populations. However, the estimates obtained may not be accurate due to infrequent mammal sightings in the area, resulting in limited data caused by the difficulty of obtaining counts of mammals within forest habitats, in addition to the difficult terrain conditions. For more accurate results, Buckland et al. (1999) recommend at least 60 observations per species. Therefore, the figures obtained from this study only serve to give a rough idea of what the status of the mammals in the ACCA is likely to be. The estimates were based on the equation:

$$
D=n . f(0) / 2 L \text {, }
$$

where $\mathrm{n}=$ the number of objects detected; $L=$ the total length of the transect lines; and, $f(0)=$ the estimated probability density evaluated at zero perpendicular distance.

Determination of the conservation status of mammal species occurring at the site was based on the IUCN Red List of Threatened Mammals (2000), and the Ghana Wildlife Conservation Regulation (LI 684, 1995).

\section{Diversity and relative abundance}

\section{Results}

A total of 24 mammal species, excluding small rodents and bats, were recorded at the site. This total included species that were reported to be present by local people, but were not seen in the surveys. Eleven (45.8\%) of these species were sighted directly or heard (e.g. forest genet) during day and night surveys. Table 1 shows species recorded and the method of recording, with the status of mammal species as perceived by hunters. 
TABLE 1

List and conservation significance of mammal species occurring around Mount Afadjato and Agumatsa Range, based on different methods of recording

Order/Family/Species

Conservation significance

Common name

Scientific name

Recording
method

Ghana wildlife

conservation

IUCN red list

Perceived by

regulation

Primates

Loridae

Demidoff's Galago

Bossman Potto

Cercopithedae

Mona monkey

Spot-nosed monkey

Galagoides demidoff

Cercopithecus mona

Cercopithecus

petaurista

Black \& White Colobus

monkey

Olive Baboon

Artiodactyla

(Ungulates)

Bovidae

Bongo

Bushback

Bay duiker

Maxwell's duiker

Black duiker

Suidae

Red river hog

Canivora

Viveridae

Slender mongoose

Dark mongoose

Forest genet

Golden cat

Sciuridae

Giant forest squirrel

Palm squirrel

Thryonomidae

Grasscutter

Hystricidae

Brush-tailed porcupine

Order/Family/Species

Common name

Colobus polykomos

Papio anubis*

Tragelaphus

euryceros

Tragelaphus scriptus

Cephalophus dorsalis

Cephalophus m.

maxwelli

Cephalophus niger

Crossarchus obscurus

Genetta genetta

Felis aurata

Protoxerus stangeri

Epixerus ebii

Thryonomimys

swinderianus

Atherurus africanus
Perodicticus potto

Potamochoerus porcus

RH

$\mathrm{RH}$

S, H, RH

S, H, RH

$\mathrm{RH}$

$\mathrm{S}$

$\mathrm{RH}$

$\mathrm{RH}$

$\mathrm{RH}$

S, RH

$\mathrm{RH}$

$\mathrm{RH}$

Herspestes sanguinues

$\mathrm{RH}$

$\mathrm{S}, \mathrm{RH}$

$\mathrm{S}, \mathrm{RH}$

$\mathrm{RH}$

$\mathrm{T}, \mathrm{RH}$

S, RH

$\mathrm{S}, \mathrm{RH}$

S, RH, FC

\begin{tabular}{lcc}
\multicolumn{2}{c}{ Conservation significance } \\
Recording & $\begin{array}{c}\text { Ghana wildlife } \\
\text { method } \\
\text { conservation } \\
\text { regulation }\end{array}$ & local people \\
& list & Perceived by \\
\end{tabular}

\section{Cricetidae}

Giant rat

Pholidota

Manidae

Tree pangolin

Long-tailed pangolin

Giant pangolin

Scientific name

Cricetomys gambianus

Manis tricuspis

Manis tetradactyla

Smutsia gigantean
CS, S, RH, FC

C

$\mathrm{RH}$

S, RH

RH
$\mathrm{R}$

U

C

C

U

C

U

LR/nt C

LR/nt C

LR/nt U

U

U

C

$\mathrm{R}$

C

U

C

U

*A troop made up of about 50 individuals was seen on the Agumatsa Range towards the Wli Waterfalls outside systematic surveys and have not been included in data analysis. 
S: Direct sighting; H: Heard; CS: Carcass seen; FP: Fecal pellets; RH: Reported by hunters but not seen during survey; T: Trophy shown. Status as perceived by local people - C: Common; U: Uncommon; R: Rare; 1 = Listed on schedule 1 of the Ghana Wildlife Conservation Regulation, i.e. Wholly protected: LR = Listed in the IUCN Red List as Low Risk; nt = Listed in the IUCN Red List as near threatened.

Thirteen of the species (54.2\%) recorded were considered common by local people, and 11 species were considered uncommon or rare (Table 1). The species considered to be common by local people were those most frequently encountered in transect counts (Table 2). The most frequently encountered species was the mona monkey (Cercopithecus mona), which accounted for $47.9 \%$ of total encounters, occurring mostly in the highlands. The number of species encoun-tered in the systematic surveys appeared to be higher in the lowland forest of Gborgame as compared to the other sites (Fig. 2a), although the difference was not significant $\left(\mathrm{F}_{3,34}=1.103, p>0.05\right)$. The number of individual species encountered also appeared higher in the highlands of Chebi as compared to other sites (Fig. 2b), although the difference was not significant $\left(\mathrm{F}_{3,34}=2.808, p>0.05\right)$.

TABLE 2

Relative abundance of mammalian species sighted within the two habitat types at the two localities

Species

Mona Monkey

Spot-nosed Monkey

Maxwell's Duiker

Slender Mongoose

Dark Mongoose

Forest Genet

Palm Squirrel

Giant Forest Squirrel

Grasscutter

Giant Rat

Long-tailed Pangolin

Total no. of species recorded

Total no. of individual sightings

Shannon-Wiener diversity index

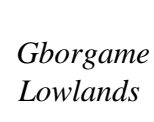

3

3

3

2

5

5

2

5

2

7

22

0.696
Number of individuals sighted

Chebi-Ahor Total Relative

Highlands Lowlands Highlands abundance\%

$\begin{array}{rrrrr}16 & 3 & 23 & 45 & 47.9 \\ 5 & & 6 & 11 & 11.7 \\ 1 & & 2 & 3 & 3.2 \\ & 1 & & 4 & 4.3 \\ & & & 2 & 2.1 \\ 1 & & & 1 & 1.1 \\ 4 & 3 & 3 & 15 & 16.0 \\ & & & 2 & 2.1 \\ & 3 & & 8 & 8.5 \\ & 1 & & 1 & 2.1 \\ & & & 2 & 2.1 \\ 5 & 5 & 4 & 11 & 100 \\ 27 & 11 & 34 & 94 & \\ 0.640 & 0.378 & 0.712 & & \end{array}$

a

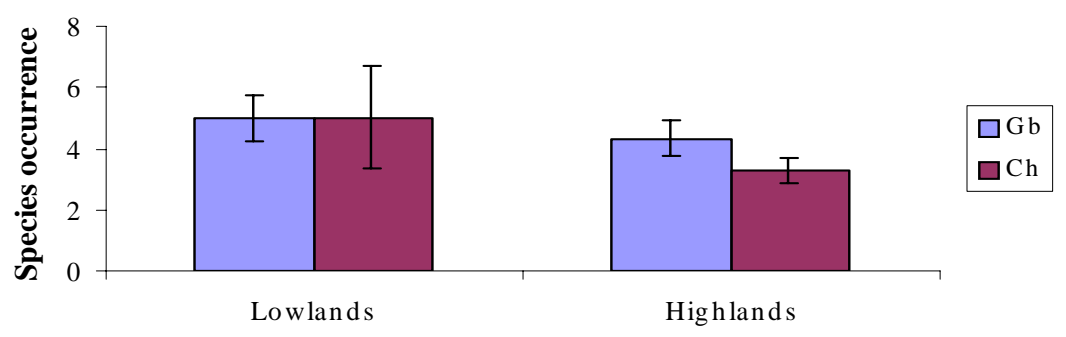

Site and $\mathrm{Habitat}$ 


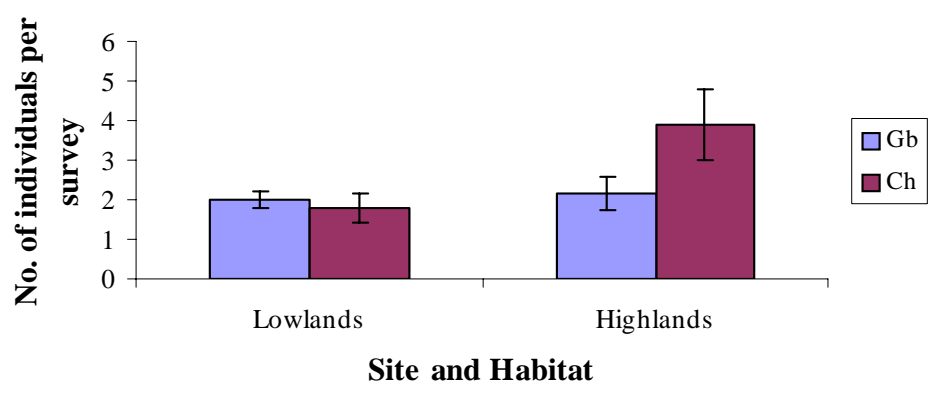

Fig. 2. Mean \pm SE of (a) mammal species occurrence; and of (b) number of individuals encountered. Gb = Gborgame; Ch = Chebi.

The number of species occurring in the lowlands tended to be higher than in the highlands (Fig. 3a), but the difference was not significant $\left(\mathrm{F}_{1,38}=2.283, p>0.05\right)$. In terms of individual encounters, the highlands tended to be higher than in the lowlands (Fig. 3b), but again this difference was not significant $\left(\mathrm{F}_{1,38}=2.830, p>0.05\right)$. The species diversity also did not differ $\left(\mathrm{F}_{1,2}=0.725, p>0.05\right)$ between the two habitat types (Table 2$)$. The overall similarity indices for species occurrence and individual encounters in the two habitat types were 0.92 and 0.67 , respectively (Fig. 4).

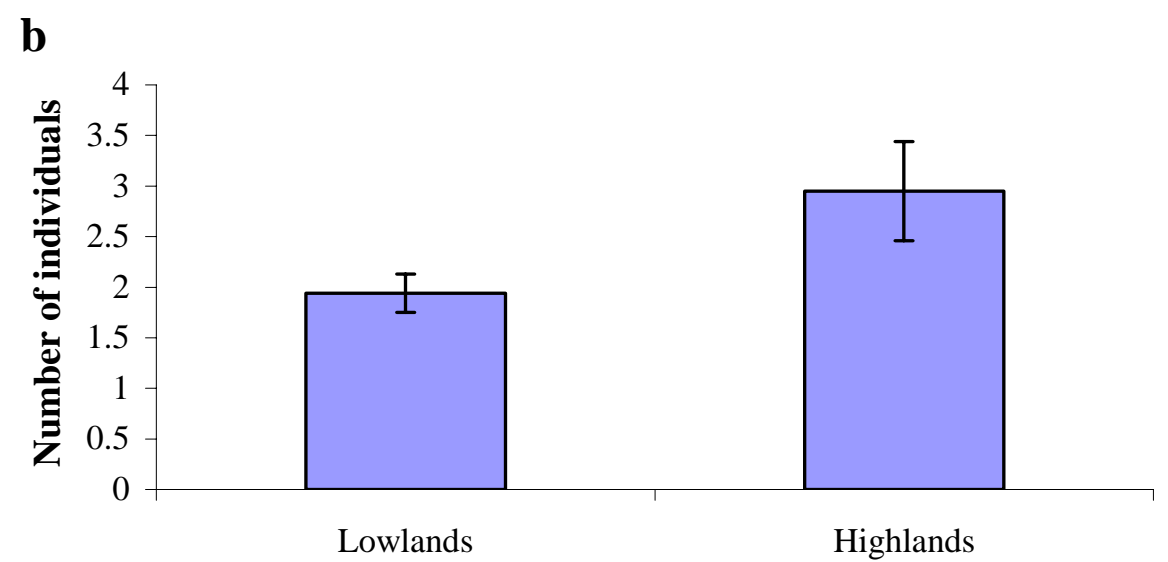

Habitat

Figure 3 Mean \pm SE of (a) mammal species occurrence; and of (b) individual encounters in the two habitat types. 

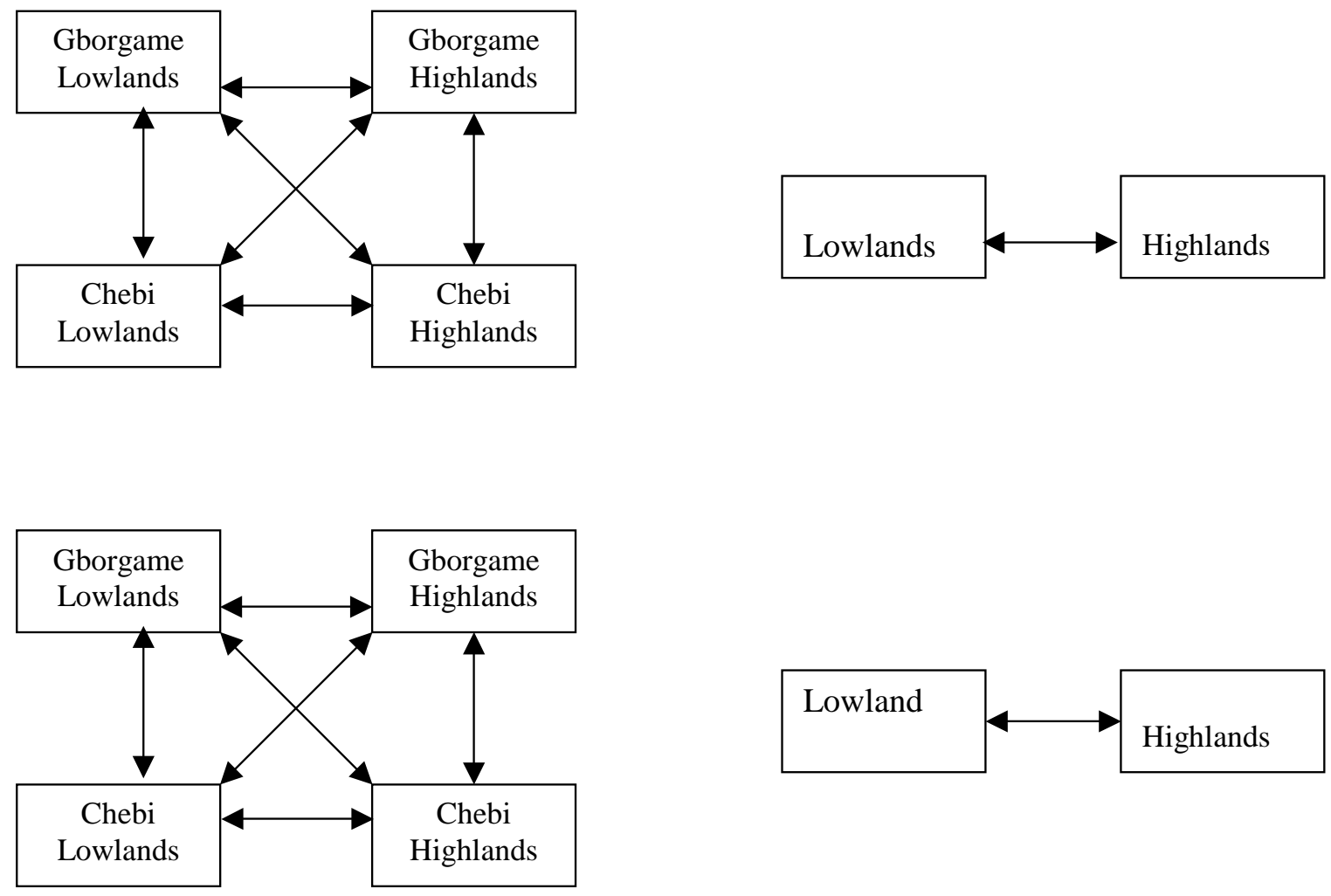

Fig 4: Similarity indices for (a) mammal species occurrence; and (b) number of individual mammals encountered in the two habitat types at the two localities. An index of 1 means complete similarity.

\section{Estimate of densities}

Calculating density estimates for each species apart from grasscutters individually was not possible because of the low number of encounters. However, an attempt was made to estimate the densities of groups of species comprising monkeys, duikers, squirrels and mongooses; and grasscutters as an individual species Table 1 provides a list of common and scientific names of all species in the various groups above whilst Table 3 provides density estimates of the above groups. The mean troop size of monkeys, comprising both mona and spot-nosed, was estimated at $2.95 \pm$ 0.39 , while the density of troops was estimated at $6.49 \pm 2.60 / \mathrm{km}^{2}$, suggesting an overall density of about 19 monkeys $/ \mathrm{km}^{2}$.

TABLE 3

Density estimates of five selected mammal groups or species in the AACA

Mammal group or species

All monkey species

All duiker species

All mongoose species

All squirrel species

Grasscutters

$$
\text { Sample size }
$$

56

3

6

17

8
Effective width of detection (m)

30.5

37.7

23.8

23.4

29.6
Estimated density $\left(\mathrm{km}^{2}\right)$

$$
\begin{array}{r}
19.1 \\
0.8 \\
2.6 \\
7.6 \\
2.8
\end{array}
$$

\section{Conservation status of mammal species}

Eleven of the species of mammals recorded in the area are at different levels of conservation concern (Table 4). These comprised three species of primates, (Galagoides demidoff, Perodicticus potto and Colobus polykomos); four species of ungulates (Tragelaphus euryceros, Cephalophus dorsalis, Cephalophus m. maxwelli and Cephalophus niger); one species of carnivore (Felis aurata) and three species belonging to the order Pholidota (Manis gigantia).

\section{Discussion}


The diversity, relative abundance and densities of mammal species at the AACA is one of the lowest in Ghanaian forests. Even though the lowland forest appeared to be more diverse, the high similarity indices suggest that the two habitat types are not significantly different in terms of diversity. The mammal fauna of the area as compared to other forest reserves in Ghana, which qualify as Important Bird Areas (IBA), is the lowest (GWS, 1999). Thus, the AACA has the lowest level of mammal species abundance among the 10 priority IBAs in Ghana (Table 4). Even the high levels of encounters with primates (in this case the mona and spot-nosed monkeys) (Table 1) at the AACA cannot be compared with what pertains in other IBAs. This suggests that the mammal fauna of the AACA clearly face an ecological crisis.

TABLE 4

Number of large mammals recorded in 10 priority IBA sites (Data from GWS, 1999)

IBA sites

Dadieso Forest Reserve

Boin-Tano Forest Reserve

Pra-Sushien Forest Reserve

Ndumfiri Forest Reserve

Tano-Nimire Forest Reserve

Atewa Range Forest Reserve

Draw River Forest Reserve

Fure River Forest Reserve

Jema Asemkro Forest Reserve

Mount Afadjato and Agumatsa Conservation Area
Number of mammals

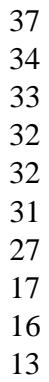

37

32

31

27

17

16

13

\section{Factors affecting diversity and abun-dance at AACA}

There is every indication that the major factors causing the decline in mammal population in the AACA are habitat degra-dation and hunting pressure. The major causes of habitat degradation in the AACA are the perennial bushfires and shifting cultivation on the mid-slopes of the mountain. Local people confirmed this during inter-views (Owusu \& Ntiamoa-Baidu, in prep.). Thus, the perennial bushfires contributing to habitat loss with consequent depletion of wildlife resources on the mountain have been of great concern to local people, government agencies and other stakeholders.

Similar observations were made at the Kakum National Park in Ghana, where heavy logging regimes under the Forestry Department management appeared to have nearly eliminated some tall forest timber species upon which at least two primates depended (Oates, 1993; Struhsaker, 1993). This, combined with intense hunting pressure, accounted for the decline in species such as the black and white colobus (Colobus vellerosus) and the diana monkey (Cercopithecus diana). Similarly, the present illegal logging in some parts of the AACA can drastically reduce animal numbers leading to a possible local extinction of certain species, since the relative abundance and density of mammal fauna is already low. As in many other studies in the West African sub-region (e.g. Jeffery, 1970; Robinson \& Peal, 1981; Ntiamoa-Baidu, 1987; Davies, 1987; Anstey, 1991; Hope-Dominik, 1991; Oates, Struhsaker \& Whitesides, 1997; Oates, 1999; Oates et al., 2000), all mammals are negatively impacted upon by rural communities. Consequently, any further delays in conservation actions is likely to deplete the mammal resources of the site, which are a very important focus for ecotourism and general economic well-being of the local people (Goodwin \& LeaderWilliams, 2000).

\section{Case for conservation and management}

It has been observed that nature reserves, national parks or sites with other conser-vation designations will always retain a central role in the conservation of animal and plant populations (Stewart \& Hutchings, 1996). Although reserves are one of a continuum of ways to manage areas of conservation concern (Groombridge, 1992), other places such as communal lands that are important for wildlife species conser-vation will need to be identified to supplement conservation efforts in designated areas. The biogeographical location of the AACA (Larsen, 1994; Owusu, 2001; Owusu \& Ntiamoa-Baidu, in prep.) makes it a very important habitat that can be promoted as a refugia for animal species known to occur and those not yet discovered in the area. However, this can be challenging, since it will mean a shift from unhindered access to some form of restriction on access. Hence, a careful planning of management activities, which does not compromise local priorities, with the full participation of local communities is likely to translate into positive actions towards the protection of the AACA and its resources. Furthermore, to add more value to the site as an IBA, it is important that mammal species are given the necessary protection to elicit support for the conservation of the site, especially as a tool for advocacy at local and national levels. It has been established that, even 
though the site appears to be rich in birds, the local people relate better to mammals than birds (Owusu, 2001). In addition, there is a high level of awareness of the declining status of mammal populations by people living in the AACA. This presents an opportunity for enhancing local support for the protection of the remaining mammals, and, thereby, rebuilding mammal populations in the AACA.

\section{Conclusion}

The species present at the AACA have been established through direct observation and hunters' reports. The low sightings and the low density of species available have also been shown. Even though the decline of natural resources is not peculiar to AACA, since they have been designated as an ecotourism site, and mammals constitute the major drawing power to such sites, there is an urgent need for more pragmatic approach to conserve the remaining wildlife without further delay.

\section{Acknowledgement}

The authors wish to thank the staff members of the Ghana Wildlife Society, particularly the forest guards at the Mt Afadjato Community Nature Reserve and Mr Isaac Olesu-Adjei, the Project Manager, for their support during data collection. The support and encouragement from Prof. Yaa Ntiamoa-Baidu of the Department of Zoology, University of Ghana, is greatly appreciated. Funding for this study was partially supported by the Royal Netherlands Embassy under the Mt Afadjato-Agumatsa Community Conservation Project.

\section{References}

Anstey S. (1991). Wildlife utilisation in Liberia. Gland, Switzerland: World Wildlife Fund.

Bodmer R. (1995). Managing Amazonian Wildlife: Biological Correlates of Game Choice by Detribalized Hunters. Ecological Applications 5: 872-877.

Buckland S. T., Anderson, D. R., Burnham K. P. and Laake J. L. (1993). Distance Sampling: Estimating Abundance of Biological Populations. London: Chapman and Hall.

Davies A. G. (1987). The Gola Forest Reserves, Sierra Leone: Wildlife Conservation and Forest Management. Gland, Switzerland: IUCN.

Decher J., Kilpatrick C. W., Bahian K. L. (2000). Small Mammal Zoogeography and Diversity in West African Forest Remnants. Progress Report to the National Geographic Society Committee for Research and Exploration (Grant 6583-99).

Ehrlich P. R. and Wilson E. O (1991). Biodiversity studies: science and policy. Science 253: 758-762.

Ghana Wildlife Society (1999). Mammal fauna of priority IBA sites. Field report submitted to the GEF/UNDP.

Ghana Wildlife Society (1998). Mount Afadjato Community Forest Conservation Project. Project Document submitted to Netherlands Development Administration.

Ghimire K. B. and Pimbert M. P. (1997). Social Change and Conservation: An Overview of Issues and Concpets. In Social Change and Conser-vation. (K. B. Ghimire and M. P. Pimbert, ed.) pp. 97-130. Earthscan Publications, UNRISD.

Goodwin H. and Leader-Williams N. (2000). Tourism and protected areas: distorting conserva-tion priorities towards charismatic megafauna? In Priorities for the Conservation of Mammalian Diversity: Has the Panda had its day? (A. Entwistle and N. Dunstone, ed.), pp.257-275. Conservation Biology 3. Cambridge University Press, Cambridge, UK.

Groombridge, B. Ed. (1992). Global biodiversity: status of the Earth's living resources. A report compiled by the World Conservation Monitoring Centre. London: Chapman and Hall.

Haltenorth T. and Diller H. (1988). A field Guide to the Mammals of Africa including Madagascar. London: Collins.

Hope-Dominik B. (1991). Distribution and status of chimpazee (Pan troglodytes verus) in the Ivory Coast. Primate Report 31: 45-75.

IUCN (2000). IUCN Red List Of Threatened Animals, Cambridge, UK: IUCN Conservation Monitoring Centre.

Jeffrey S. (1970). Ghana's forest wildlife in danger. Oryx 10: 240-243.

Jenkins M. (1992). Species extinction. In Global biodiversity. (B. Groombridge, ed.), pp. 192-205. London: Chapman \& Hall.

Kingdon J. (1997). The Field Guide to African Mammals. London: Academic Press.

Larsen T. (1994) The butterflies of Ghana-their implications for conservation and sustainable use. Accra, Ghana Wildlife Dept. (Unpubl. report.)

Mace G. and Balmford A. (2000). Patterns and processes in contemporary mammalian extinction. In Priorities for the Conservation of Mammalian Diversity: Has the Panda had its day? (A. Entwistle and N. Dunstone, ed.), pp. 27-52. Conservation Biology 3. Cambridge, UK: Cambridge University Press.

Magurran A. E. (1988). Ecological Diversity and Its Measurement. Princeton University Press. 
Ntiamoa-Baidu Y., Owusu E. H., Daramani D. T. and Nuoh A. A. (2001). Ghana. In Important Bird Areas in Africa and associated islands Priority sites for conservation. (L. D. C. Fishpool and M. I. Evans, ed.), pp. 367389. Newbury and Cambridge, UK: Pisces Publications and BirdLife International (BirdLife Conservation Series No. 11).

Oates J. F. (1993). Kakum National Park, Ghana. Wildlife Specialist's Report on visit of 9-29 August 1993. Conservation International Report, unpublished.

Oates J. F., Struhsaker T. T. and Whitesides G. H. (1997). Extinction faces Ghana's red colobus monkey and other locally endemic subspecies. Primate Conserv. 17: 138-144.

Oates J. F. (1999). Myth and reality in the rain forest: How conservation strategies are failing in West Africa. Berkeley: California University Press.

Oates J. F., Abedi-Lartey M., McGraw W. S., Struhsaker T. T. and Whitesides G. (2000). Extinction of a West African red colobus monkey. Conserv. Biol. 14: 1526-1532.

Owusu E. H. (2001). Community-based conservation in Ghana: the potential of the Afadjato and Agumatsa Range for ecotourism. (PhD Thesis.) University of Kent at Canterbury, Kent, UK.

Robbinson P. T. and Peal A. (1981). Liberia's Wildlife: A time for decision. Zoonoz. 54: 20-27.

Stewart A. J. A. and Hutchings M. J. (1996). Conservation of populations. In Conservation Biology. (I. F. Spellerberg, ed.), pp. 122-140. England: Longman Group Ltd.

Struhsaker T. T. (1993). Ghana's forest and primates. Report of a field trip to Bia and Kakum National Parks and Boabeng-Fiema Monkey Sanctaury. Conservation International.

Wilson D. E., Cole F. R., Nicholas J. D., Rudran R. and Foster M. S (1997). Measuring and Monitoring Biological Diversity: Standard Methods for Mammals. Washington, D. C.: Smithsonian Institution Press. 